Supporting Information For:

\title{
Structural tunability on naphthalimide-based dendrimer gelators via glaser coupling interaction with tailored gelation solvent polarity and stimuli-responsive properties
}

Junqi Ge ${ }^{\dagger,}$, Jiangbo Guo ${ }^{\ddagger}$, Xudong $\mathrm{Yu}^{*, \hbar}$, Yajuan $\mathrm{Li}^{\ddagger}$, Zichuan $\mathrm{Ma}^{*}, \dagger$

${ }_{\dagger}$ College of Chemistry and Material Science, Hebei Normal University, Shijiazhuang 050024, China

\$College of Science and Hebei Research Center of Pharmaceutical and Chemical Engineering, Hebei University of Science and Technology, Shijiazhuang 050080, China E-mail for corresponding author: chemyxd@163.com (X.Yu); mazc@vip.163.com (Z. Chuan)

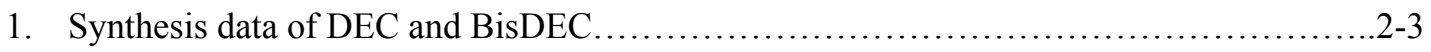

2. Preparation and photos of low-molecular-weight organogels...................................4-6

3. Spectral characterization data of solution and gels of DEC and BisDEC ......................6-8

4. SEM and TEM images of xerogels.............................................................

5. Rheological and other data of DEC and BisDEC gel................................... 9-11 
1. Synthesis data of DEC and BisDEC
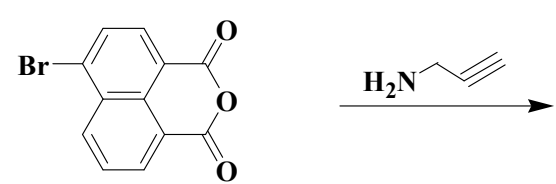
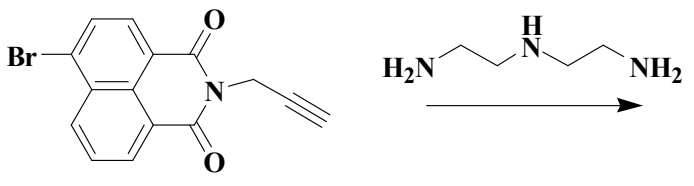

1<smiles>C#CCN1C(=O)c2cccc3c(NCCNCCN)ccc(c23)C1=O</smiles>

2
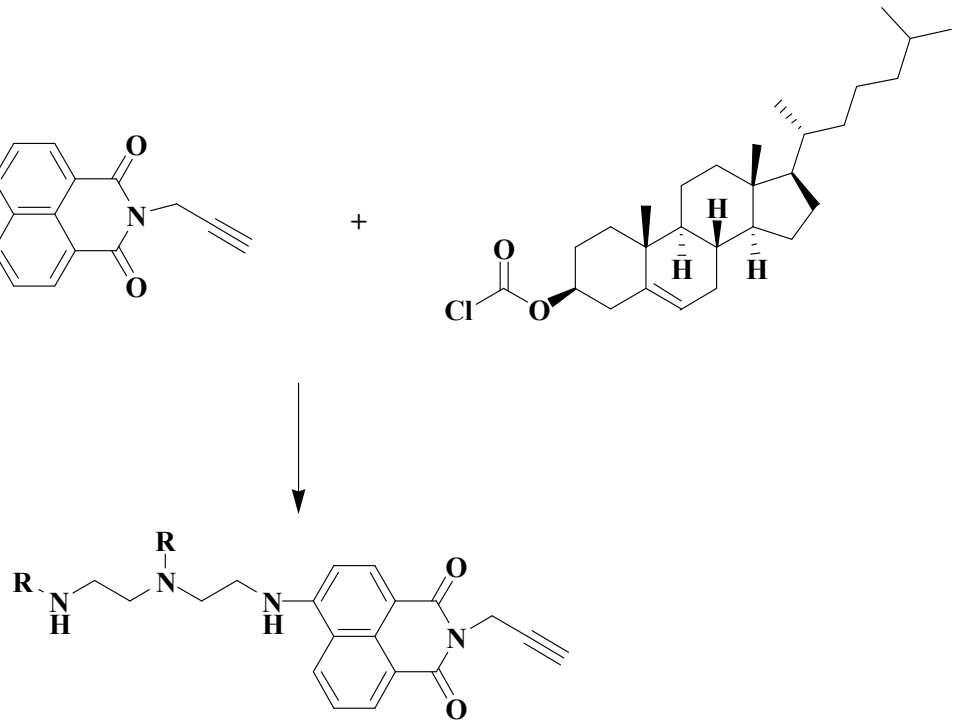

DEC

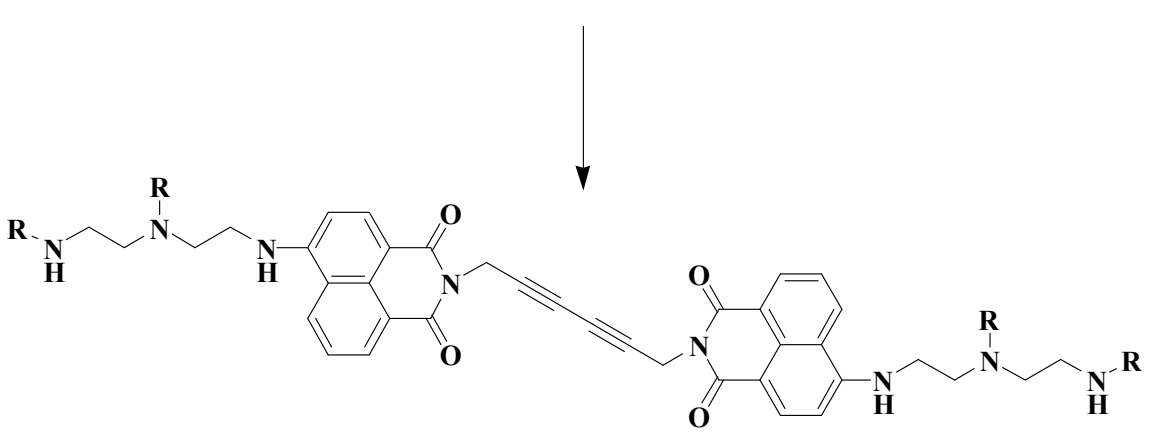

BisDEC

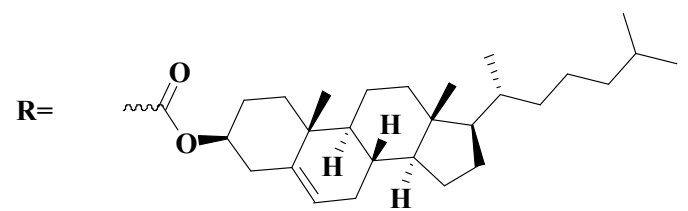

Scheme $\mathrm{S} 1$. The synthesis procedure of DEC and BisDEC.

Synthesis of 1: 4-Br-1, 8-naphthalic anhydride (277 mg, $1 \mathrm{mmol})$ and propargylamine (54 mg, 1 mmol) were refluxed in 2-methoxyethanol for 24 hours. The mixture was then concentrated and purified by column chromatography $\left(\mathrm{SiO}_{2}: \mathrm{CH}_{2} \mathrm{Cl}_{2} / \mathrm{CH}_{3} \mathrm{OH}=100: 1 \mathrm{v} / \mathrm{v}\right)$ to yield 1 as a white solid (191 mg, 60\%). Mp: 239-241 ${ }^{\circ} \mathrm{C}$; ${ }^{1} \mathrm{HNMR}\left(500 \mathrm{M}, \mathrm{CDCl}_{3}, \delta\right): 2.22-2.23$ (t, $\left.1 \mathrm{H}, \mathrm{J}=2.5 \mathrm{~Hz}\right), 4.98(\mathrm{~d}$, $2 \mathrm{H}, \mathrm{J}=2.5 \mathrm{~Hz}), 7.88-7.91(\mathrm{t}, 1 \mathrm{H}, \mathrm{J}=8 \mathrm{~Hz}), 8.08-8.10(\mathrm{~d}, 1 \mathrm{H}, \mathrm{J}=8 \mathrm{~Hz}), 8.48-8.50(\mathrm{~d}, 1 \mathrm{H}, \mathrm{J}=7.5$ $\mathrm{Hz}), 8.64-8.63(\mathrm{~d}, \mathrm{~J}=8.5 \mathrm{~Hz}), 8.72-8.74(\mathrm{~d}, 1 \mathrm{H}, \mathrm{J}=7.5 \mathrm{~Hz})$.

Synthesis of 2: Compound 1 ( $314 \mathrm{mg}, 1 \mathrm{mmol})$, diethylenetriamine (1.03 g, 10mmol) were refluxed in ethanol for 24 hours, then ethanol was removed under vacuum, and the reaction mixture was 
purified by column chromatography to yield 2 as a yellow solid $(71.3 \mathrm{mg}, 21.2 \%)$. Mp: $>250{ }^{\circ} \mathrm{C}$; ${ }^{1} \mathrm{HNMR}$ (500M, DMSO, $\delta$ ): 2.36 (s, 1H), 2.65 (d, 2H, J = 5.5 Hz), 2.69 (d, 2H, J = 6.5 Hz), 2.87 (t, $2 \mathrm{H}, \mathrm{J}=12.5 \mathrm{~Hz}), 3.08(\mathrm{t}, 2 \mathrm{H}, \mathrm{J}=4.5 \mathrm{~Hz}), 3.48(\mathrm{t}, 2 \mathrm{H}, \mathrm{J}=12.5 \mathrm{~Hz}), 6.85(\mathrm{~d}, 1 \mathrm{H}, \mathrm{J}=9 \mathrm{~Hz}), 7.69-$ $7.74(\mathrm{t}, 1 \mathrm{H}, \mathrm{J}=15.5 \mathrm{~Hz}), 8.30$ (d, 1H, J = 8.5 Hz), 8.48 (d, 1H, J = 7 Hz), 8.74 (d, 1H, J = $8 \mathrm{~Hz}$ ). MS calc. for $[\mathrm{C} 19 \mathrm{H} 20 \mathrm{~N} 4 \mathrm{O} 2+\mathrm{H}]^{+}: 337.16$; found: 337.10

Synthesis of DEC: Compound 2 (336 mg, 1 mmol), (3ß)-cholest-5-en-3-yl carbonochloridate (898 $\mathrm{mg}, 2 \mathrm{mmol}$ ) and $6 \mathrm{~mL} \mathrm{Et} 3 \mathrm{~N}$ were stirred in dry $\mathrm{CHCl}_{3}$ for two days, then the reaction mixture was concentrated and purified by column chromatography $\left(\mathrm{SiO}_{2}, \mathrm{CH}_{2} \mathrm{Cl}_{2} / \mathrm{CH}_{3} \mathrm{OH}=90: 1 \mathrm{v} / \mathrm{v}\right)$, yellow solid was obtained (597 mg, 51.3\%). Mp: 173.0-176.4 ${ }^{\circ} \mathrm{C} ;{ }^{1} \mathrm{HNMR}\left(500 \mathrm{M}, \mathrm{CDCl}_{3}, \delta\right): 0.66(\mathrm{~s}, 8 \mathrm{H})$, $0.94-0.77$ (m, 26H), $0.98(\mathrm{~s}, 7 \mathrm{H}), 1.10(\mathrm{~s}, 13 \mathrm{H}), 1.19-1.59(\mathrm{~m}, 26 \mathrm{H}), 1.87(\mathrm{~m}, 10 \mathrm{H}), 2.25(\mathrm{~s}, 1 \mathrm{H})$, $2.65(\mathrm{~s}, 2 \mathrm{H}), 2.89(\mathrm{~d}, 2 \mathrm{H}, \mathrm{J}=30 \mathrm{~Hz}), 3.13(\mathrm{~s}, 2 \mathrm{H}), 3.55(\mathrm{~d}, 4 \mathrm{H}, \mathrm{J}=31.5 \mathrm{~Hz}), 6.88(\mathrm{~d}, 1 \mathrm{H}, \mathrm{J}=9 \mathrm{~Hz})$, $7.67(\mathrm{t}, 1 \mathrm{H}, \mathrm{J}=15.5 \mathrm{~Hz}), 8.30(\mathrm{~d}, 1 \mathrm{H}, \mathrm{J}=8.5 \mathrm{~Hz}), 8.47(\mathrm{~d}, 1 \mathrm{H}, \mathrm{J}=7 \mathrm{~Hz}), 8.62(\mathrm{~m}, 1 \mathrm{H}) .{ }^{13} \mathrm{C} \mathrm{NMR}$ (500 MHz, $\left.\mathrm{CDCl}_{3}, \delta\right): 11.87,18.73,19.34,21.04,22.57,22.82,23.84,24.28,28.01,29.13,29.70$, $31.85,35.79,36.18,38.61,39.48,39.71,42.31,50.00,56.14,56.67,70.02,74.76,79.30,103.39$, $109.24,120.36,122.70,124.75,127.53,129.89,131.47,139.34,150.41,156.31,158.41,163.22$, 164.00. Anal. Calcd. For: $\mathrm{C}_{75} \mathrm{H}_{110} \mathrm{~N}_{4} \mathrm{O}_{6}: \mathrm{C}, 77.41 ; \mathrm{H}, 9.53$; N, 4.81; Found: C, 77.39; H, 9.55; N, 4.85 .

Synthesis of BisDEC: Compound DEC (1.2 g, $1 \mathrm{mmol}), \mathrm{Cu}(\mathrm{OAc})_{2}(199 \mathrm{mg}, 1 \mathrm{mmol})$ were heated in pyridine at $60{ }^{\circ} \mathrm{C}$ for $10 \mathrm{~h}$, then the reaction mixture was concentrated and purified by Column chromatography $\left(\mathrm{SiO}_{2}, \mathrm{CH}_{2} \mathrm{Cl}_{2} / \mathrm{CH}_{3} \mathrm{OH}=100: 1 \mathrm{v} / \mathrm{v}\right)$, resulting in yellow solid (697 mg, yield: $\left.60 \%\right)$. Mp: 184.3-186.4 ${ }^{\circ} \mathrm{C} ;{ }^{1} \mathrm{HNMR}\left(500 \mathrm{M}, \mathrm{CDCl}_{3}, \delta\right): 0.68$ (s, 12H), $0.75-1.75$ (m, 144H), 1.93 (m, 19H), $2.31(\mathrm{~m}, 6 \mathrm{H}), 2.86(\mathrm{~s}, 9 \mathrm{H}), 3.39-3.84(\mathrm{~m}, 11 \mathrm{H}), 6.69(\mathrm{~d}, \mathrm{~J}=77.5 \mathrm{~Hz}, 2 \mathrm{H}), 7.57$ (s, 2H), 8.08 $-8.66(\mathrm{~m}, 6 \mathrm{H}) .{ }^{13} \mathrm{C} \mathrm{NMR}\left(500 \mathrm{MHz}, \mathrm{CDCl}_{3}, \delta\right): 11.88,18.74,19.30,21.05,22.57,22.83,23.87$, 24.26, 28.02, 29.36, 29.7, 31.86, 35.81, 36.20, 38.53, 39.53, 39.74, 42.32, 50.01, 56.17, 56.69, 74.72 . Anal. Calcd. For: $\mathrm{C}_{150} \mathrm{H}_{218} \mathrm{~N}_{8} \mathrm{O}_{12}$ : C, 77.48; H, 9.45; N, 4.82; Found: C, 77.49; H, 9.50; N, 4.78. 


\section{Preparation and photos of low-molecular-weight organogels}

Table S1. The gelation properties of DEC $(25 \mathrm{mg} / \mathrm{mL})$ in organic solvents

\begin{tabular}{|c|c|c|c|c|}
\hline solution & $\mathbf{R}$ & $\mathbf{U}$ & H-C & H-U \\
\hline n-pentane & $\mathrm{G}$ & $\mathrm{G}$ & S & $\mathrm{S}$ \\
\hline dichloromethane & $\mathrm{S}$ & $\mathrm{S}$ & S & $\mathrm{S}$ \\
\hline cyclopentane & $\mathrm{S}$ & $\mathrm{S}$ & S & $\mathrm{S}$ \\
\hline acetone & I & I & I & $\mathrm{I}$ \\
\hline trichloromethane & $\mathrm{S}$ & $\mathrm{S}$ & S & $\mathrm{S}$ \\
\hline methanol & I & I & I & I \\
\hline tetrahydrofuran & $\mathrm{S}$ & $\mathrm{S}$ & S & $\mathrm{S}$ \\
\hline n-Hexane & G & G & S & $\mathrm{S}$ \\
\hline cyclohexane & $\mathrm{S}$ & $\mathrm{S}$ & $\mathrm{S}$ & $\mathrm{S}$ \\
\hline petroleum ether & $\mathrm{G}$ & $\mathrm{G}$ & S & $\mathrm{S}$ \\
\hline ethyl acetate & I & I & I & I \\
\hline ethanol & I & I & I & I \\
\hline benzene & $\mathrm{S}$ & $\mathrm{S}$ & S & $\mathrm{S}$ \\
\hline 2-propanol & I & I & I & I \\
\hline tert-Butanol & I & I & I & I \\
\hline n-propanol & I & I & I & I \\
\hline 2-butyl alcohol & I & I & I & I \\
\hline 1,4-dioxane & $\mathrm{S}$ & $\mathrm{S}$ & S & $\mathrm{S}$ \\
\hline methylbenzene & $\mathrm{S}$ & $\mathrm{S}$ & $\mathrm{S}$ & $\mathrm{S}$ \\
\hline butyl Alcohol & I & I & I & I \\
\hline 2-methoxyethanol & I & I & I & I \\
\hline 1-Pentanol & I & I & I & I \\
\hline 2-amyl alcohol & I & I & I & I \\
\hline dimethylbenzene & $\mathrm{S}$ & $\mathrm{S}$ & S & $\mathrm{S}$ \\
\hline $\mathrm{N}, \mathrm{N}$-dimethylformamide & I & I & I & I \\
\hline cyclohexanol & I & I & I & $\mathrm{I}$ \\
\hline benzaldehyde & $\mathrm{S}$ & $\mathrm{S}$ & S & $\mathrm{S}$ \\
\hline dimethyl sulfoxide & I & I & I & I \\
\hline
\end{tabular}

Note: I: insoluble; G: gel; S: solution; R: resting process; U: ultrasound; H-C: heating-cooling process; H-U:

Heating-ultrasound process.

Table S2. The gelation properties of BisDEC $(25 \mathrm{mg} / \mathrm{mL})$ in organic solvents.

\begin{tabular}{ccccc}
\hline solution & R & U & H-C & H-U \\
\hline n-pentane & I & I & I & I \\
dichloromethane & S & S & S & S \\
cyclopentane & S & S & S & S \\
acetone & I & I & I & I \\
trichloromethane & S & S & S & S \\
methanol & I & I & I & I \\
tetrahydrofuran & S & S & S & S \\
\hline
\end{tabular}




\begin{tabular}{ccccc}
\hline n-Hexane & I & I & I & I \\
cyclohexane & I & I & S & S \\
petroleum ether & I & I & I & I \\
ethyl acetate & I & I & I & I \\
ethanol & I & I & I & I \\
benzene & S & S & S & S \\
2-propanol & I & I & I & I \\
tert-Butanol & I & I & I & I \\
n-propanol & I & I & I & I \\
2-butyl alcohol & I & I & G & P \\
1,4-dioxane & I & I & I & I \\
methylbenzene & S & S & S & S \\
butyl Alcohol & I & I & G & P \\
2-methoxyethanol & I & I & I & I \\
1-Pentanol & I & I & G & P \\
2-amyl alcohol & I & I & G & P \\
dimethylbenzene & S & S & S & S \\
N, N-dimethylformamide & I & I & I & I \\
cyclohexanol & I & I & G & P \\
benzaldehyde & S & S & S & S \\
dimethyl sulfoxide & I & I & I & I \\
\hline
\end{tabular}

Note: I: insoluble; G: gel; S: solution; R: resting process; U: ultrasound; H-C: heating-cooling process; H-U:

Heating-ultrasound process.

Table S3. $\mathrm{T}_{\mathrm{g}}$ of the DEC gels (left) and BisDEC gels in typical solvents.

\begin{tabular}{cccc}
\hline solution & $\mathrm{T}_{\mathrm{g}}$ of DEC & solution & $\mathrm{T}_{\mathrm{g}}$ of BisDEC \\
\hline n-pentane & $48{ }^{\circ} \mathrm{C}$ & butyl alcohol & $94^{\circ} \mathrm{C}$ \\
n-hexane & $50{ }^{\circ} \mathrm{C}$ & n-pentanol & $92^{\circ} \mathrm{C}$ \\
\hline
\end{tabular}

\section{Spectral characterization data of solution and gels of DEC and BisDEC}

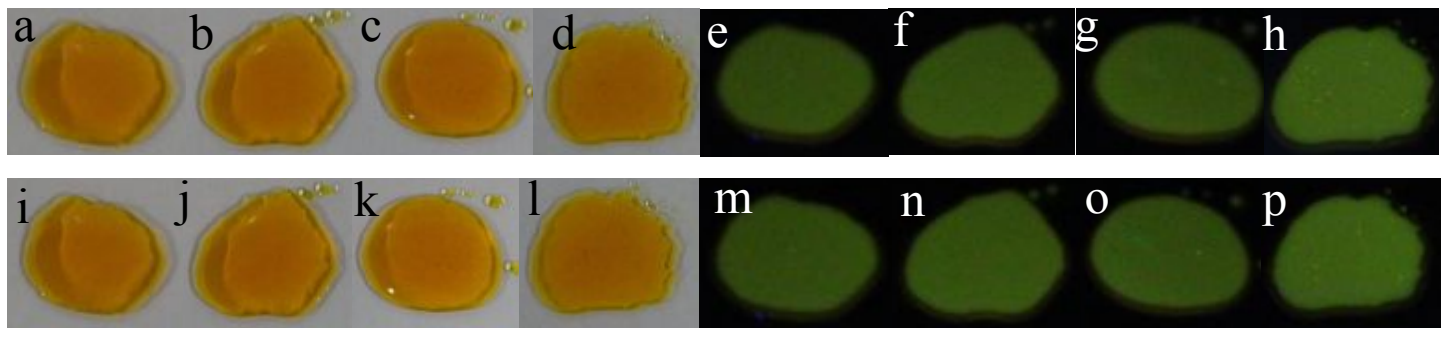

Figure S1. Photos of DEC gels before and after treatment of acid and alkali in light and in dark (up: before treatment with acid and alkali, down: after treatment with acid and alkali): a), e): DEC gel in n-pentane; i), m): DEC gel in n-pentane treated with hydrochloric acid; b), f): DEC gel in n-hexane; j), n): DEC gel in n-hexane treated with acetic acid; c), g): DEC gel in n-pentane; k), o): DEC gel 
in n-pentane treatment with ammonia water; d), h): DEC gel in n-hexane; 1), p): DEC gel in nhexane treated with triethylamine.

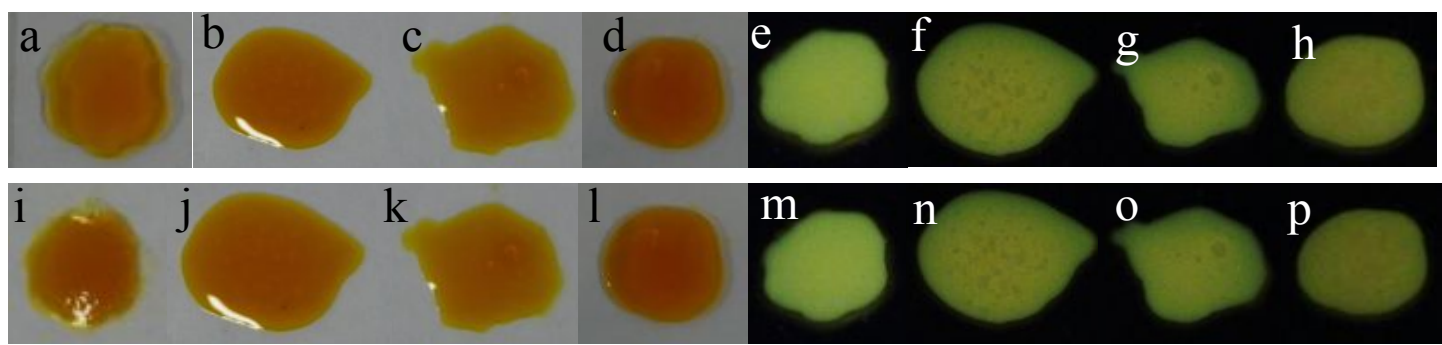

Figure S2. Photos of BisDEC gels before and after treatment of acid and alkali in light and in dark (up: before treatment with acid and alkali, down: after treatment with acid and alkali): a), e): BisDEC gel in n-pentanol ; i), m): BisDEC gel in n-pentanol treated with hydrochloric acid; b), f): BisDEC gel in cyclohexanol; j), n): BisDEC gel in cyclohexanol treated with acetic acid; c), g): BisDEC gel in n-pentanol; k), o): BisDEC gel in n-pentanol treated with ammonia water; d), h): BisDEC gel in cyclohexanol; 1), p) BisDEC gel in cyclohexanol treated with triethylamine.

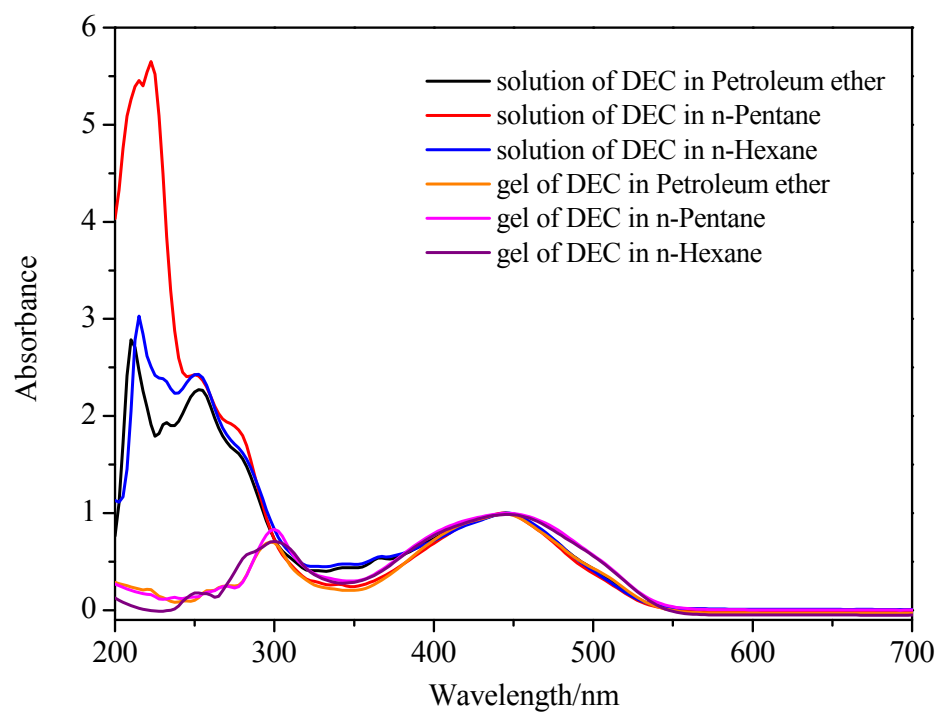

Figure S3. UV-vis spectra of the DEC solution $\left(10^{-5} \mathrm{M}\right)$ and gel $(25 \mathrm{mg} / \mathrm{mL})$. 


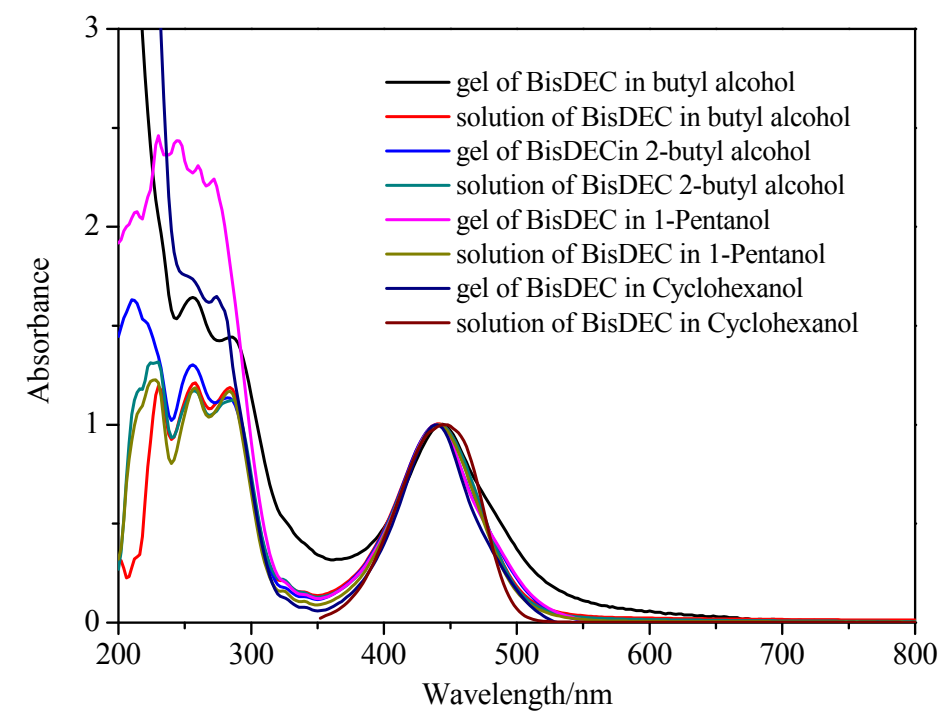

Figure S4. a) UV-vis spectra of the BisDEC solution $\left(10^{-5} \mathrm{M}\right)$ and gel $(25 \mathrm{mg} / \mathrm{mL})$.

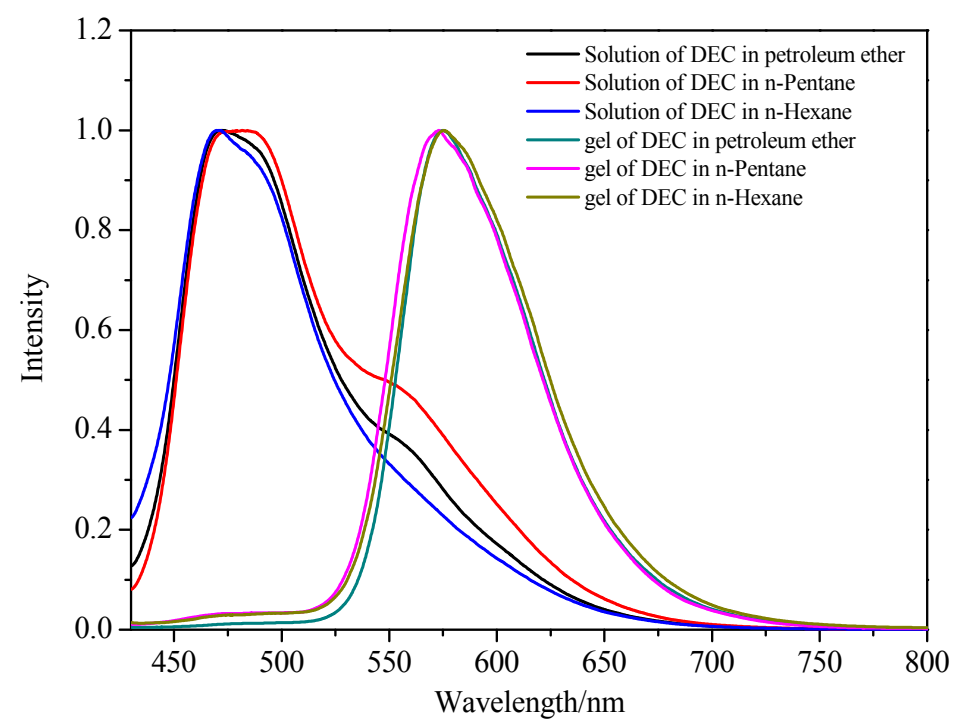

Figure S5. fluorescence spectra of the DEC solution $\left(10^{-5} \mathrm{M}\right)$ and gel $(25 \mathrm{mg} / \mathrm{mL})$. 


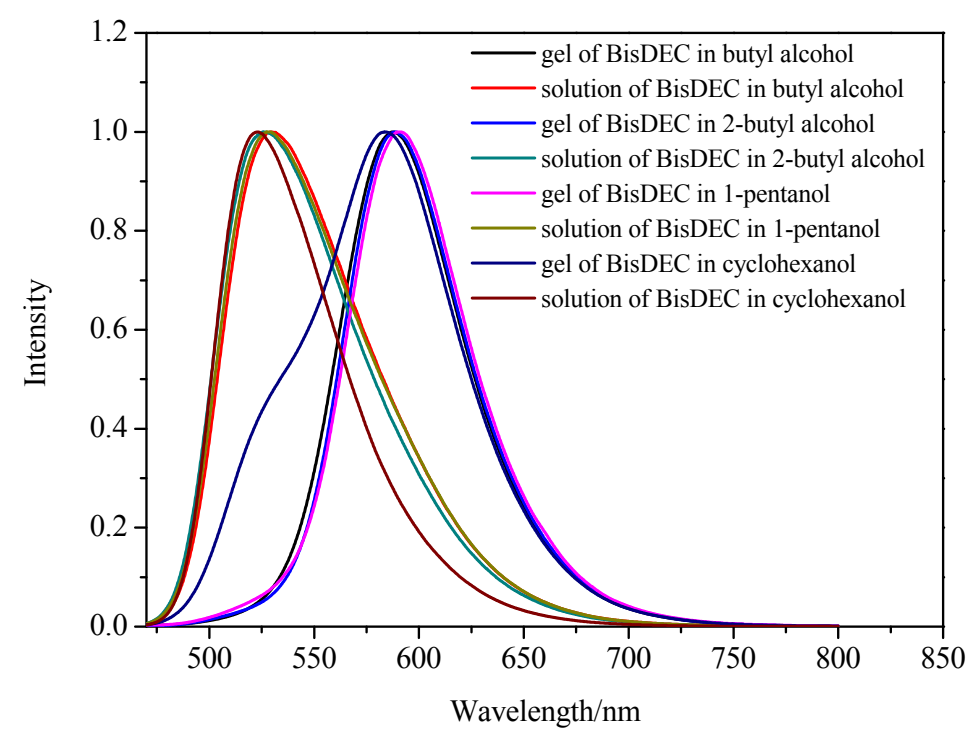

Figure S6. fluorescence spectra of the BisDEC solution $\left(10^{-5} \mathrm{M}\right)$ and gel $(25 \mathrm{mg} / \mathrm{mL})$.

\section{SEM and TEM images of xerogels}

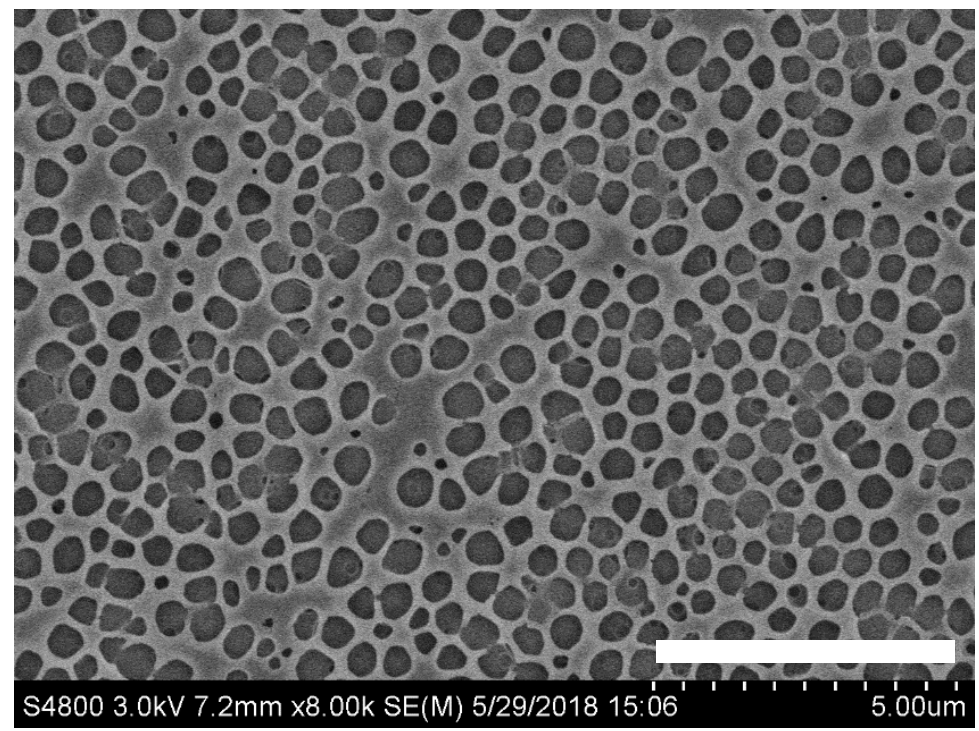

Figure S7. Honeycomb structure of DEC xerogel from n-pentane. Scale bar: $5 \mu \mathrm{m}$;
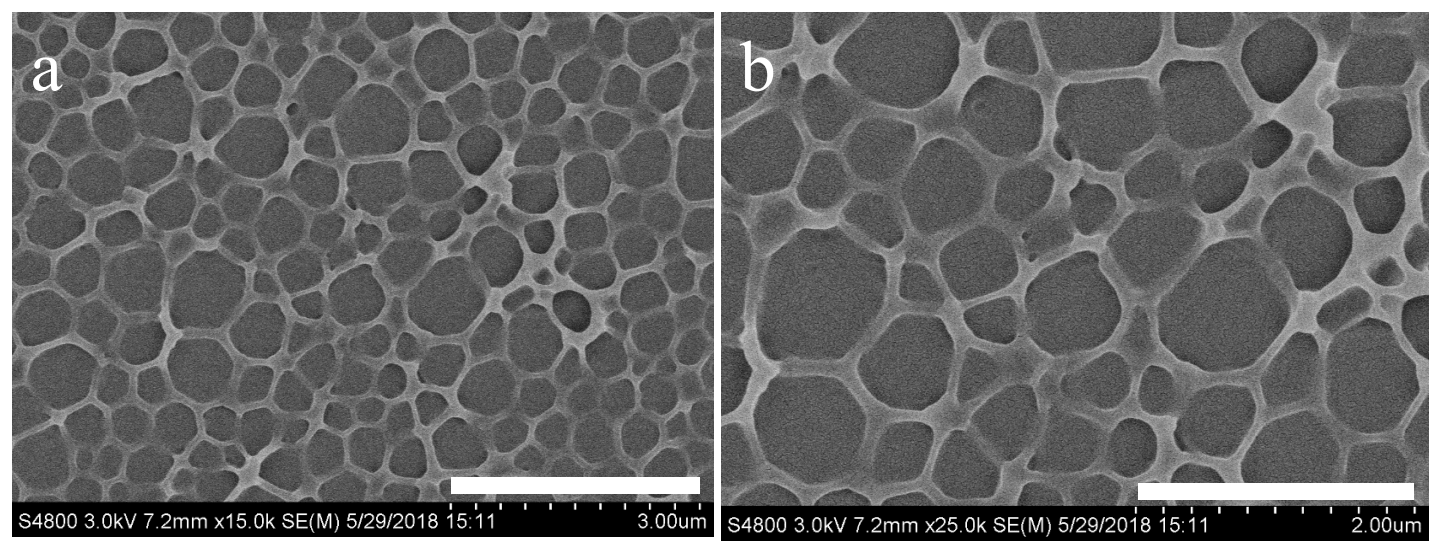
Figure S8. a) SEM image of DEC xerogel from n-hexane; b) magnification picture of a). Scale bar: a) $3 \mu \mathrm{m}$; b) $2 \mu \mathrm{m}$.

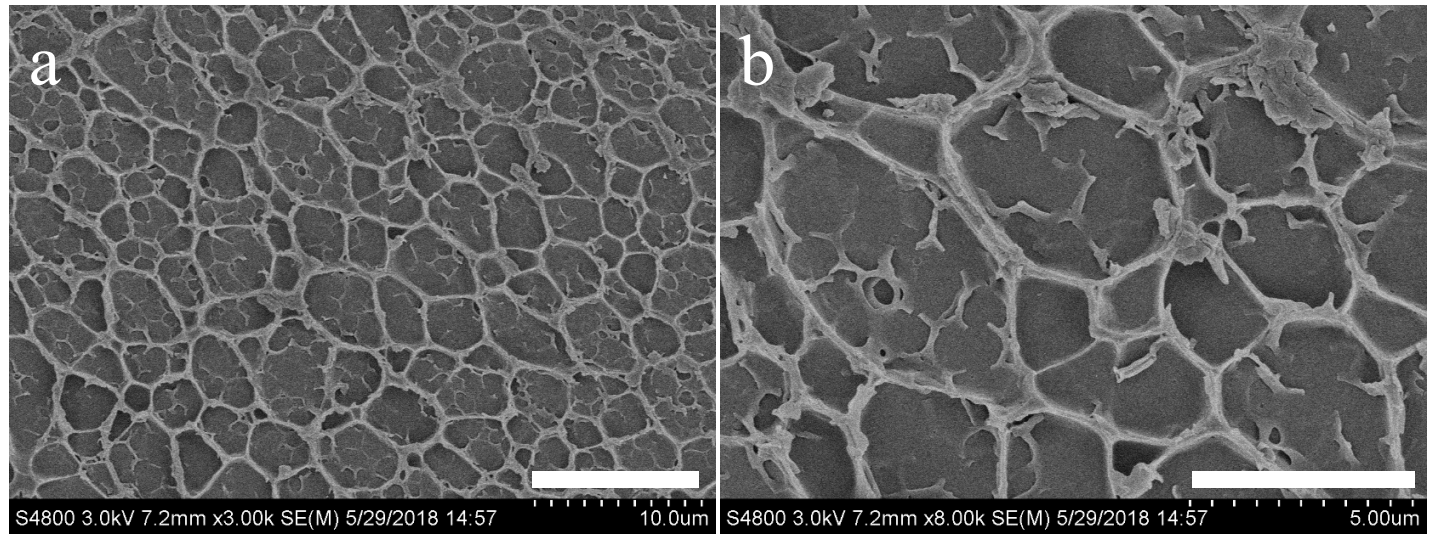

Figure S9. a) SEM image of DEC xerogel from petroleum; b) magnification picture of a). Scale bar:

a) $10 \mu \mathrm{m}$; b) $5 \mu \mathrm{m}$.
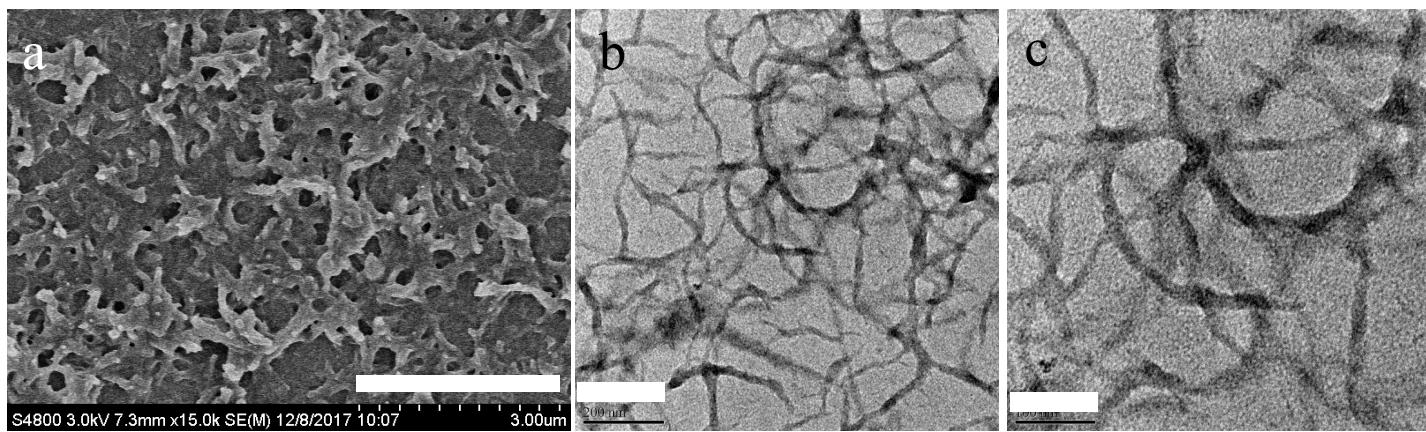

Figure S10. a) SEM image of xerogels of the BisDEC from n-butanol; b) TEM image of BisDEC xerogel from n-butanol; c) magnification picture of b). Scale bar: a) $3 \mu \mathrm{m}$; b) $200 \mathrm{~nm}$; c) $100 \mathrm{~nm}$.

\section{Rheological and other data of DEC and BisDEC gels}
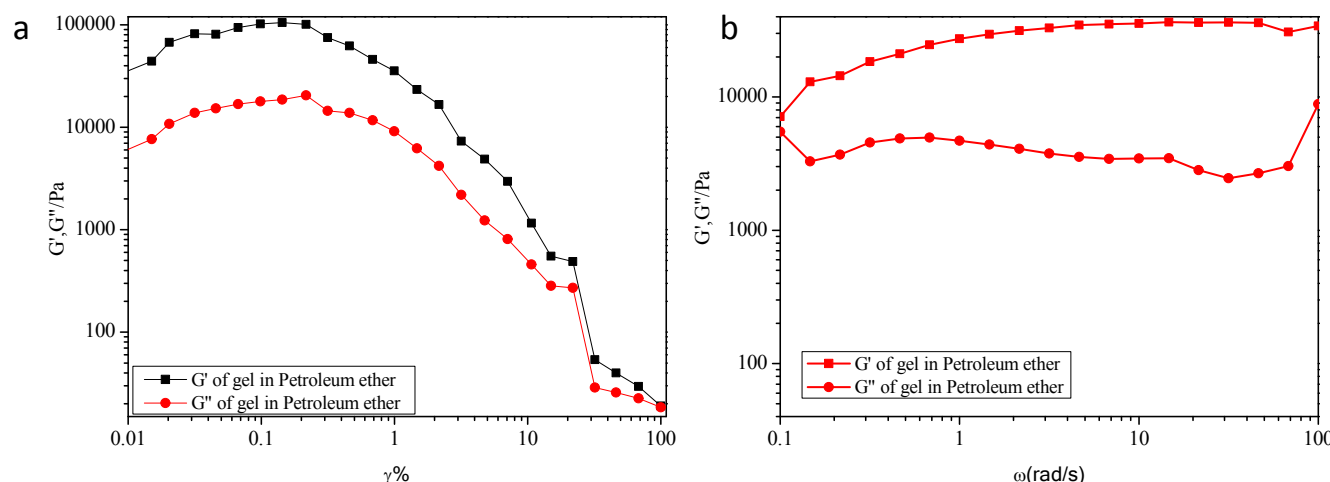

Figure S11. a) Dynamic strain sweep measurement of DEC gel in petroleum ether $(25 \mathrm{mg} / \mathrm{mL})$ with angular frequency at $10 \mathrm{rad} / \mathrm{s}$; b) Frequency dependency of $\mathrm{G}^{\prime}$ and $\mathrm{G}^{\prime \prime} \quad$ for DEC gel in petroleum ether $(25 \mathrm{mg} / \mathrm{mL})$ with strain at $0.1 \%$. 
a

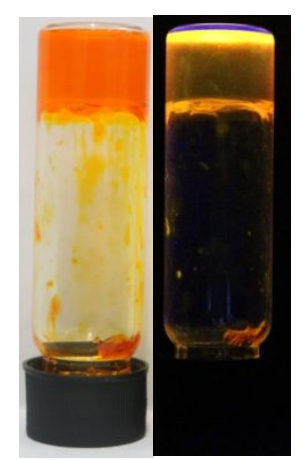

$\mathrm{b}$

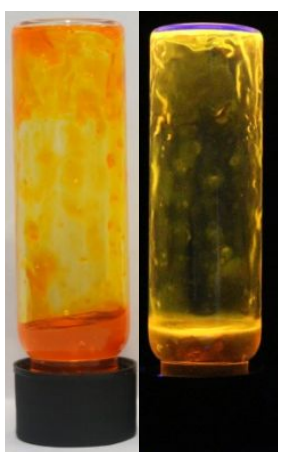

$\mathrm{C}$

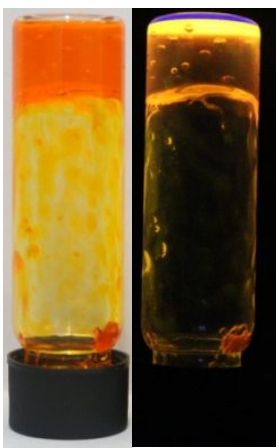

Figure S12 (a-c) Thixotropic experiment of the DEC gel in petroleum ether $(25 \mathrm{mg} / \mathrm{mL})$ a) images of DEC gel; b) collapsed gel triggered by shaking; c) recovered gel after minutes.

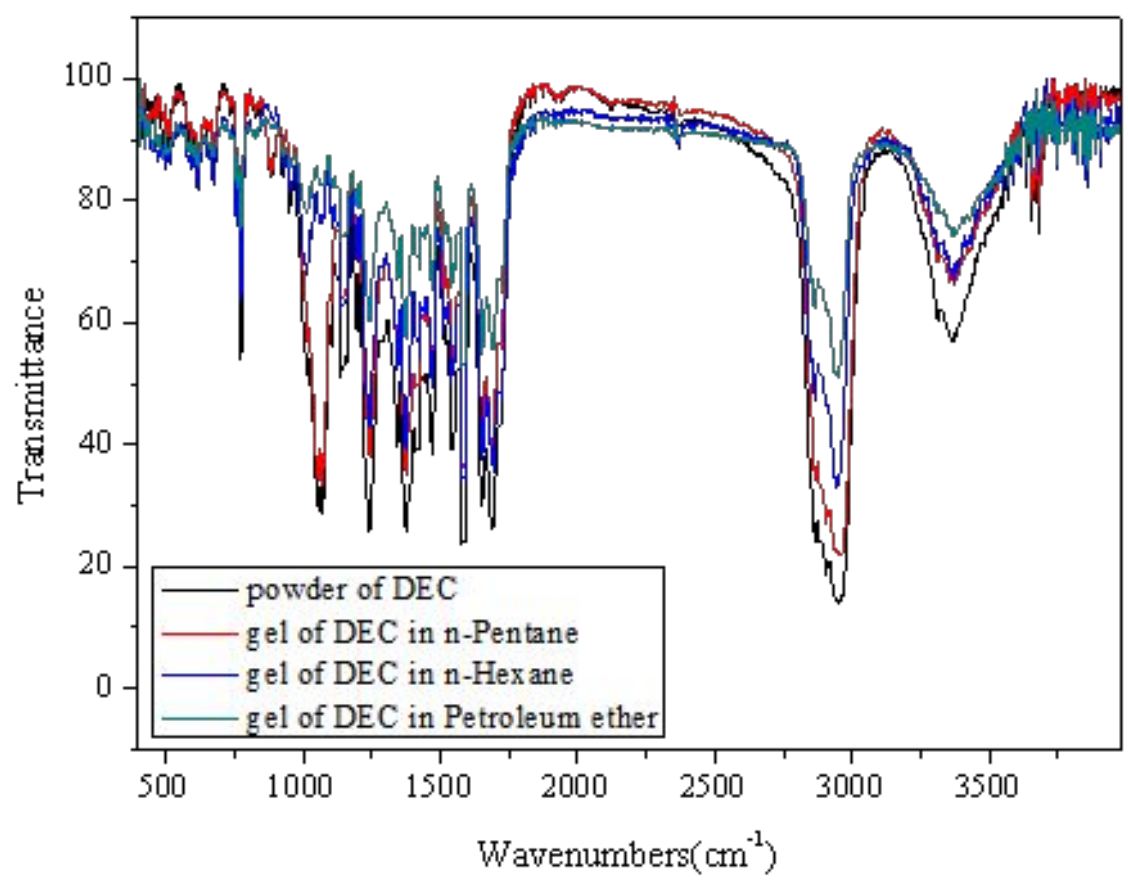

Figure S13 IR spectra of DEC powder and xerogels. 


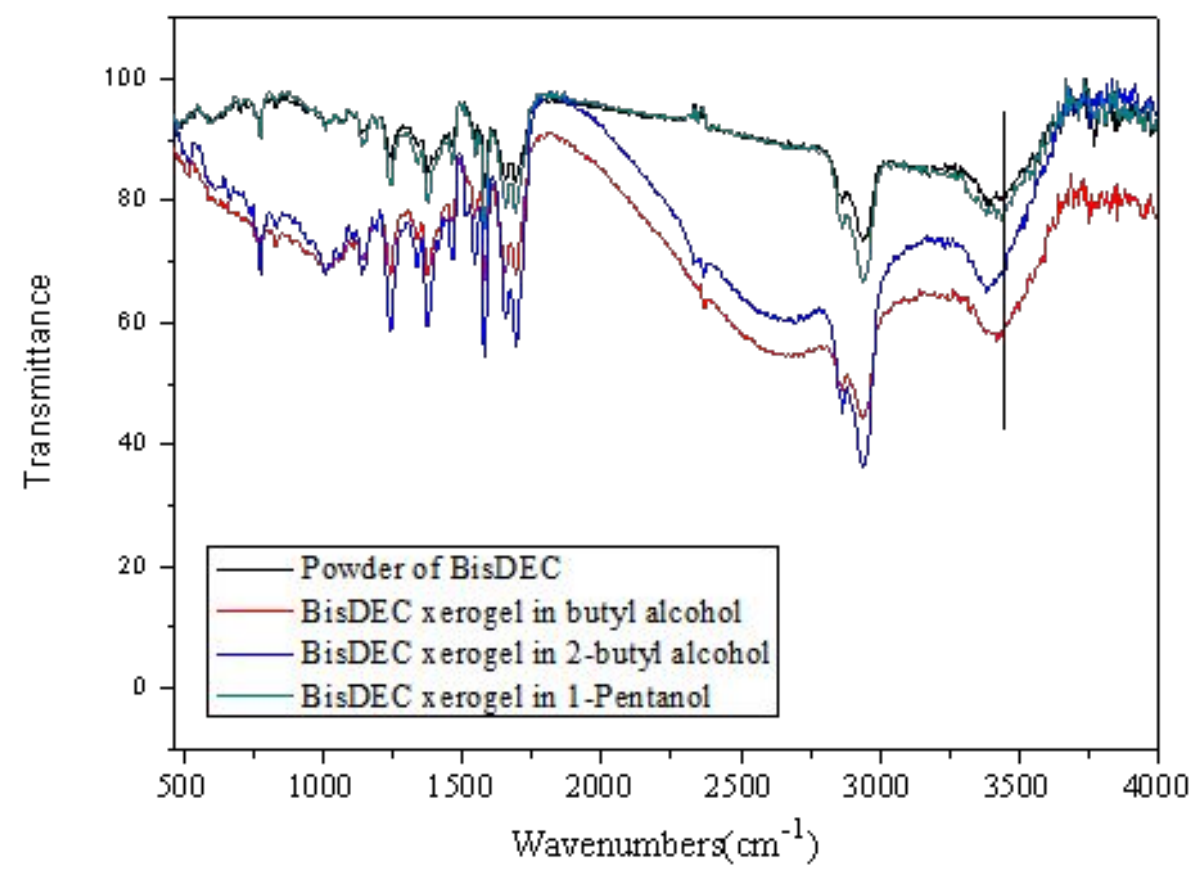

Figure S14 IR spectra of BisDEC powder and xerogels.

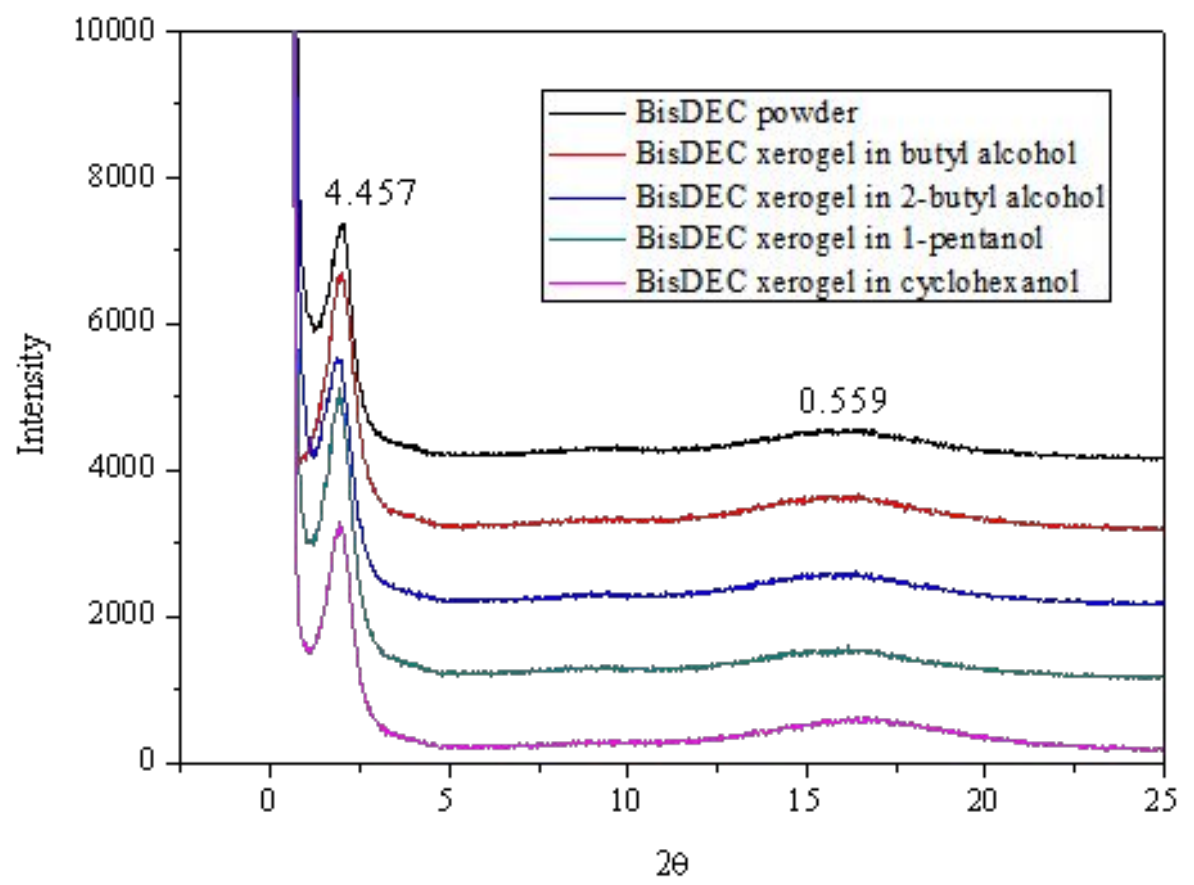

Figure S15 XRD spectra of BisDEC xerogels from different solvents. 